\title{
Feasibility and Efficacy of Willpower Strengthening Exercises with University Students: A Randomised Control Pilot Study
}

\author{
Aileen M. Pidgeon, Sophie L. Monteath \\ Department of Psychology, Bond University, Gold Coast, Australia \\ Email: sophie.monteath@gmail.com
}

Received August 2013

\begin{abstract}
This study examined the feasibility and efficacy of implementing intense brief willpower strengthening exercises with university students. Thirty-nine university students were randomly allocated into one of three groups: willpower strengthening exercise intervention groups, 4-7-8 Hands or postural adjustments, or a control group. Participants assigned to the active intervention groups were required to practice the relevant willpower strengthening exercise every hour, for six hours per day, over three days. The high participation and compliance rates of participants in the two active intervention groups, along with positive feedback, supported the feasibility of the willpower strengthening exercises with university students. Additionally, the 4-7-8 Hands and posture groups reported directional improvements in willpower compared to the control group. Future research is recommended to evaluate the efficacy of willpower strengthening exercises over a longer time period to allow for more practice and effect time.
\end{abstract}

Keywords: Willpower Strengthening; Self-Control; Feasibility; Efficacy

\section{Introduction}

Willpower gives us the strength to persevere (Baumeister \& Tierney, 2011). However, perseverance can be difficult to maintain when the desired goal is challenging to achieve, as the harder it becomes for an individual to continue to exercise selfcontrol, the higher the risk the individual's willpower becomes depleted (Baumeister, Heatherton, \& Tice, 1994). Willpower is the capacity an individual requires to exert self-control. Selfcontrol refers to overriding and altering dominant responses achieved by controlling thoughts, feelings, and behaviours, which involves higher-order cognitive processes overriding lower-order cognitive processes (Baumeister et al., 1994). For example, when an individual's goal is to quit smoking, they need the willpower to resist the desire to smoke. The higherorder cognitive process is the goal to quit smoking and the lower-order cognitive process is the desire to smoke. Self-control involves refraining from smoking and denying the lowerorder cognitive process, i.e. the desire to smoke for short-term pleasure. When an individual's lower-order cognitive process dominates their higher-order cognitive process, such as engaging in smoking behaviour, it is referred to as self-control failure (Baumeister et al., 1994). Research suggests that self-control failure can lead to negative consequences such as morbid obesity, criminal behaviour, and drug and alcohol abuse (Oaten \& Cheng, 2006b).

Although willpower is a desirable trait, many individuals acknowledge a lack of willpower strength. A recent survey conducted by the American Psychological Association (2010), revealed that Americans rated lack of willpower as the number-one reason for not achieving goals. Due to the important role that willpower has in preventing negative consequences, as well as the high demand for willpower strength, this present study investigated the feasibility of implementing intense brief willpower strengthening exercises with university students, and evaluating the efficacy of these exercises on improving university students' willpower.

Baumeister et al.'s (1994) theory of willpower is comprised of four domains: emotional control, thought control, performance control, and impulse control. This theory is a focus of the present study, as previous investigations into willpower strength expressed through each domain has not been carried out. Emotion control refers to the ability to regulate feelings and mood, and typically involves avoiding a negative emotion and desiring more pleasant emotions (Baumeister \& Tierney, 2011). Thought control, refers to the ability to intentionally focus attention on a train of thought (Baumeister et al., 1994). Mindfulness, a skill for intentionally observing a train of thought, involves the self-control of attention on immediate experiences, such as thoughts, emotions, and body sensations, in the present moment without judgement (Chiesa \& Malinowski, 2011). The third domain of willpower, performance control, refers to persevering with a task when quitting seems very appealing, or regulating performance to ensure efforts are on target to achieve a desired goal. Finally, impulse control refers to the ability to resist temptations to achieve high-order desired goals (Baumeister \& Tierney, 2011).

Previous research has found an association between high levels of willpower and high levels of self-control success. However, as willpower energy is exerted to execute self-control, ego depletion occurs. Ego depletion refers to the temporary diminished capacity for an individual to exercise self-control, due to exhausted willpower, which is caused by prior execution of self-control (Baumeister et al., 1998). Baumeister et al. (1998) tested the hypothesis of ego depletion by conducting an experimental comparison study with college students, who were randomised into two experimental groups: radish group and cookies group. Participants in both groups were presented simultaneously with both radishes and cookies. Participants in the radish group were instructed to only eat the radishes, while 
the participants in the cookies group were instructed to only eat the cookies. Participants who ate the radishes instead of the cookies were considered to have exercised self-control by refraining from eating the more desirable food, cookies. After this task, both groups were given exactly the same unsolvable puzzles to solve. Participants were not informed that the puzzles were not solvable. The results indicated that compared to the cookies group, the radish group, who restrained from eating cookies, tended to exhibit higher ego depletion, as measured by their efforts on the unsolvable puzzles. Participants in the radish group tended to exert significantly less effort on the puzzles compared to the cookies group. In Baumeister et al.'s study, participants' ego depletion was assessed by their performance control. Those who quit sooner on the puzzle tasks were considered as having had the greatest ego depletion. However, a limitation of this study was that ego depletion was measured across only one of the four domains of willpower, and generalised the results to rely on the unproven assumption that the amount of willpower required to exercise self-control is the same across all four domains. This present study addressed this limitation by examining the effects of willpower strengthening exercises across the four domains of willpower including, emotional control, thought control, performance control, and impulse control.

The results obtained from Baumeister et al.'s (1998) study led to development of the limited resource model which hypothesised that exerting self-control in one domain would deplete the resource of willpower and increase the likelihood of selfcontrol failure in another domain. The limited resource model also postulated that willpower operates similar to a muscle, i.e. a muscle has finite strength and becomes fatigued when utilised or exercised. When a muscle is fatigued it becomes globally weak across all forms of physical exertion, not just in the specific exercise that caused fatigue, which is similar to ego depletion. Resting for a period of time seems to replenish the muscle's strength, which is analogous to how the resource of willpower is replenished.

Muraven, Baumeister, and Tice (1999) extended the theory that willpower is analogous to a muscle, by hypothesising that certain tasks can be used to strengthen willpower, similar to how certain exercises can strengthen muscles. A muscle can be strengthened, by increasing either baseline capacity, or stamina, which results in a reduction to vulnerability to fatigue when exerted. Muraven et al.'s (1999) randomised control study investigated the effects of a number of willpower strengthening exercises on improving willpower in university students. These exercises included repeated practice of postural adjustments, striving to maintain a positive mood, and keeping a food diary. The results suggested that the groups who practised postural adjustments and recorded their food intake, compared to striving for positive moods and the control groups, were less vulnerable to ego depletion after being subjected to a self-control task. Limitations of Muraven et al.'s study include ego depletion being measured in terms of only one domain of willpower, namely, performance control, and failure to standardise the regularity in which participants carried out the willpower strengthening exercises. For example, participants in the posture condition were instructed to correct their posture whenever they remembered to do so. Muraven et al. did attempt to control for compliance to the exercises, by requesting participants to complete a monitoring diary. Participants who returned the diary at the completion of the study were considered to have complied with carrying out the willpower strengthening exercises. However, a limitation of this study was the assessment of compliance, which was based on whether participants solely returned their diary material, as opposed to whether the participants actually recorded carrying out the assigned exercises. This current study addressed these limitations by standardising the regularity of carrying out the willpower strengthening exercises by providing participants with a bracelet set to vibrate on the wrist once an hour, indicating to the participant when to carry out the relevant willpower strengthening exercise. Additionally, assessment of compliance to complete the willpower strengthening exercises was based on completion of the monitoring sheets provided.

This present randomised control pilot study aimed to evaluate the feasibility and efficacy of willpower strengthening techniques to increase willpower in university students. Additionally, previous research by Oaten and Cheng (2006a) suggests that university students' experience of stress has the potential to be alleviated through willpower strengthening.

This current study evaluated the effects of intensive brief willpower strengthening exercises, carried out over a short period of time, of three days. Muraven et al. (1999) utilised willpower strengthening interventions over a two-week period, which resulted in significant improvements in willpower strength. The rationale for utilising an intensive, short-term approach to strengthening willpower was to increase both recruitment and compliance to complete the exercises as instructed, as well as to reduce attrition rates from the study due to the high work-load and time constraints placed on students (Hughes, 2005).

The intensive brief willpower strengthening exercises included regular standardised postural adjustments and a mindfulness-based exercise. Past research has indicated that mindfulness meditation can decrease ego-depletion (Friese, Messner, \& Schaffner, 2012). For example, Friese et al.’s (2012) study investigated the effects of mindfulness meditation on replenishing willpower with middle-aged individuals who completed a three-day introductory mindfulness meditation seminar. The results indicated that participants who utilised their mindfulness skills in situations demanding self-control, they were less vulnerable to ego depletion. However, a limitation of this study was that mindfulness skills were developed through meditation practice and therefore requires considerable investment of effort and time, which may reduce the feasibility to utilise with a university student population (Segal, Williams, \& Teasdale, 2002). Therefore, this current study addressed this limitation by evaluating the utility of a brief practical mindfulness-based exercise to strengthen willpower.

The effect of willpower strengthening exercises on improving willpower in this current study was measured in terms of improvements across Baumeister et al.’s (1994) four components of willpower including, emotional control, thought control, performance control, and impulse control. Perceived stress and distress tolerance were used to assess control of emotions. Participants' mindfulness was assessed to evaluate levels of thought control. As previously explained, mindfulness involves regulation of reactions to thoughts, and mindfulness-based exercises have been shown to improve self-control (Friese et al., 2012). However, further investigation is required to evaluate the efficacy of willpower strengthening exercises on increasing levels of mindfulness, and hence control over reactions to thoughts. This current study aimed to evaluate this interaction. 
Performance control was assessed using self-reported perceptions of performance control. Past research has typically utilised practical means to assess performance control by testing participants' vulnerability to underregulation or quitting tasks prematurely (Murvaen et al., 1999; Oaten \& Cheng, 2006a, 2006b). However, failure to exert performance control can be either due to underregulation or misregulation, which involves not regulating efforts towards an intended goal, therefore this study utilised a self-report measure as a more comprehensive assessment to include both underregulation and misregulation (Baumeister et al., 1994).

Finally, the domain of willpower, impulse control, was assessed in this present study through an iPad version of the Stroop colour-word task, called The Stroop Effect (Bebebe Co., 2011). This iPad application was derived from the fundamental principles of Sroop's (1935) original test. The task is a test of impulse control, as it requires individuals to actively override the dominant, impulsive response, to read the word stimulus, and substitute it with the secondary response of identifying the colour of the word (Muraven \& Baumeister, 2000). The iPad Stroop task was administered twice in each session. During each session, in between the two testings, participants were asked to exercise thought control by not thinking of a white bear. This thought suppression task draws on the principles from Wegner, Schneider, Carter, and White's (1987) initial studies into controlling thoughts of not thinking of a white bear. If the thought suppression task required participants to utilise their willpower and exhibit thought control, it was expected participants would perform worse on the second Stroop task, compared to the first, due to ego depletion. This measure of impulse control has been used and validated in other self-control studies (Baumeister, Gailliot, DeWall, \& Oaten, 2006). Therefore a Stroop task coupled with a thought suppression task was selected to measure impulse control. However, Stroop tasks are often criticised as not only assessing impulse control but also measure a participant's practice effects (Davidson, Zacks, \& Williams, 2003). Practice effects become more pronounced the longer participants practice the test (Davidson et al., 2003). The version of the Stroop test used in this study was selected as it is brief. Additionally the Stroop version iPad application provided an innovative and technologically advanced dimension to the study.

On the basis of the research presented it was hypothesised that the utilisation of intense brief willpower strengthening exercises with university students would be feasible and compared to the control group, the willpower strengthening exercise groups would show significant improvements in willpower strength across all four domains.

\section{Methodology}

\section{Participants}

A total of 39 university students participated in this study. Participants were aged from 17 to 50 years $(M=24.46, S D=$ 9.36). The sample was comprised of 36 females (92\%) and three males (8\%).

\section{Materials}

Emotion control was measured using two self-report inventories.

Perceived Stress Scale-10 (PSS-10; Cohen \& Williamson,
1988) is a 10-item, self-report scale designed to measure an individual's appraisal of life situations as stressful. The items are typically general in nature, as opposed to focusing on specific events (e.g., "In the last month, how often have you felt nervous and 'stressed'?”). Participants were asked to rate items on a 5-point Lickert scale, ranging from 0 (never) to 4 (always). Higher scores indicate greater perceived stress, though there are no cut-off scores. Chronbach's alpha has found to have ranged from .74 to .91 and test-retest ranged from .72 to .90 (Lee, 2012).

Distress Tolerance Scale (DTS; Simons \& Gaher, 2005) is a 15-item, self-report scale that assesses individuals' appraisal of their ability to tolerate emotional distress. The scale has a single, second-order, general distress tolerance factor and four firstorder factors. Participants were asked to rate each item (e.g., "Feeling distressed or upset is unbearable to me.") on a 5-point Lickert scale, ranging from 1 (Strongly agree) to 5 (Strongly disagree). Higher scores indicate higher distress tolerance, though there are no cut-off scores. Chronbach's alpha was strong and reported at 89 (Cougle et al., 2012), and test-retest reliability was reported at .61 (Simons \& Gaher, 2005).

Thought control was measured using one self-report inventory.

Mindfulness Attention Awareness Scale (MAAS; Brown \& Ryan, 2003) is a 15-item, self-report inventory, designed to assess dispositional mindfulness in individuals of an unspecified age group. Participants are asked to indicate how frequently they experience each item (e.g., "I find myself doing things without paying attention.”). Frequency was rated on a 6-point Lickert scale, ranging from 1 (almost always) to 6 (almost never). Higher scores indicate greater mindfulness. The MAAS has a moderate to high degree of internal consistency, with a reported Chonbach alpha of .82, and test-retest reliability of .81 (Brown \& Ryan, 2003).

Performance control was measured using one self-report inventory.

Brief Self-Control Scale (BSCS: Tangney et al., 2004) developed to assess behavioural self-control in individuals, is a 13-item, five-factor, self-report questionnaire. All factors tend to reflect the specific domain of willpower, performance control (de Ridder, Lensvelt-Mulders, Finkernauer, Stok, \& Baumeister, 2012). Items (e.g., "I am lazy”) were rated on a 5-point Likert scale, ranging from 1 (not at all like me) to 5 (very much like me). Higher scores indicate stronger self-control, though there are no cut-off scores. The BSCS has a high degree of internal consistency with a reported Chonbach alpha at .85 and test-retest reliability at .87 .

Impulse control was measured using an iPad version of the Stroop colour-word task (Stroop, 1935), The Stroop Effect (Bebebe Co., 2011). Individuals were asked to identify the ink colour of a word and ignore the content of the word. Participants responded by tapping, with their finger, on one of these answers presented at the bottom of the screen. If a participant answered correctly, a new critical stimulus appeared. If a participant answered incorrectly, the screen momentarily flashed red and the participant attempted to respond again. Participants had 30 seconds to identify the ink colour of as many words as possible. A participant's total score was the sum of the number of correct answers minus the number of incorrect answers.

The impulse control task was administered twice during one session, and in between completing the two testings, participants completed a thought suppression task (Wegner et al., 
1987). The thought suppression task involved participants writing their current thoughts for five minutes, while not thinking of a white bear. The difference in total scores of the Stroop task, before and after the thought suppression task, was assessed in each session, to measure the change due to ego depletion.

\section{Procedure}

Participants were randomly allocated into one of three conditions (Control, Posture, and 4-7-8 Hands). Randomisation involved a computer generated randomisation number sequence, which randomly allocated participants at the time of recruitment. The Posture and 4-7-8 Hands groups were active intervention groups and required to carry out relevant willpower strengthening exercises. Participants in the Posture group were instructed to adjust their posture, while participants in the 4-7-8 Hands group were requested to carry out a brief mindfulness-based technique, 4-7-8 Hands (Institute for Mindfulness Studies, 2011), which is a breathing and hand movement task.

Participants were tested in two laboratory sessions, pre-test and post-test, spaced three days apart. Figure 1 depicts the procedures for pre-test, which comprised of six phases. The first five phases were generic for all participants, in which random allocation to a group type and testing of all dependent variables occurred. The sixth phase was segregated by group allocation. The Control group was instructed to leave the room while the 4-7-8 Hands and Posture groups watched relevant brief video tutorials. The instructional videos were created by the researchers and provided verbal instructions with visual demonstrations, of the respective willpower strengthening ex- ercises. Individuals listened to the video instructions on separate computer screens, with headphones, to ensure they only heard and saw the relevant instructions. The video tutorials ensured standardised protocols of the procedures of how to implement the willpower strengthening exercises. Additionally, participants were given an information sheet on their respective willpower strengthening exercise. The different modes of delivery of instructions were designed to meet a breadth of different participants' learning styles, to increase understanding, comprehension, and mastery of the relevant willpower strengthening exercise, as well as to enhance compliance to carrying out the exercises.

During the three days between testing sessions, the two experimental groups, Posture and 4-7-8 Hands, were instructed to wear a Meaning to Pause ${ }^{\circledR}$ bracelet (Graham \& Irish, 2010) for six hours a day. Meaning to Pause ${ }^{\circledR}$ bracelets are commercially bought, inexpensive devices that give a gentle and private vibration once an hour. They were used to standardise how often participants practiced the willpower strengthening exercises. Once an hour the bracelet vibrated, signalling participants to carry out the relevant willpower strengthening exercise. Participants were instructed to keep a record of compliance of carrying out the willpower strengthening exercise by completing a self-monitoring form. To enhance compliance, 4-7-8 Hands and Posture Groups were sent standardised reminder text messages each morning, at $9 \mathrm{am}$, to wear their bracelets and carry out their exercises, as well as thanking them for participating in the study.

After three days, all participants returned for post-test. This session consisted of the identical four phases of testing that were administered in the first laboratory session (see Figure 2).

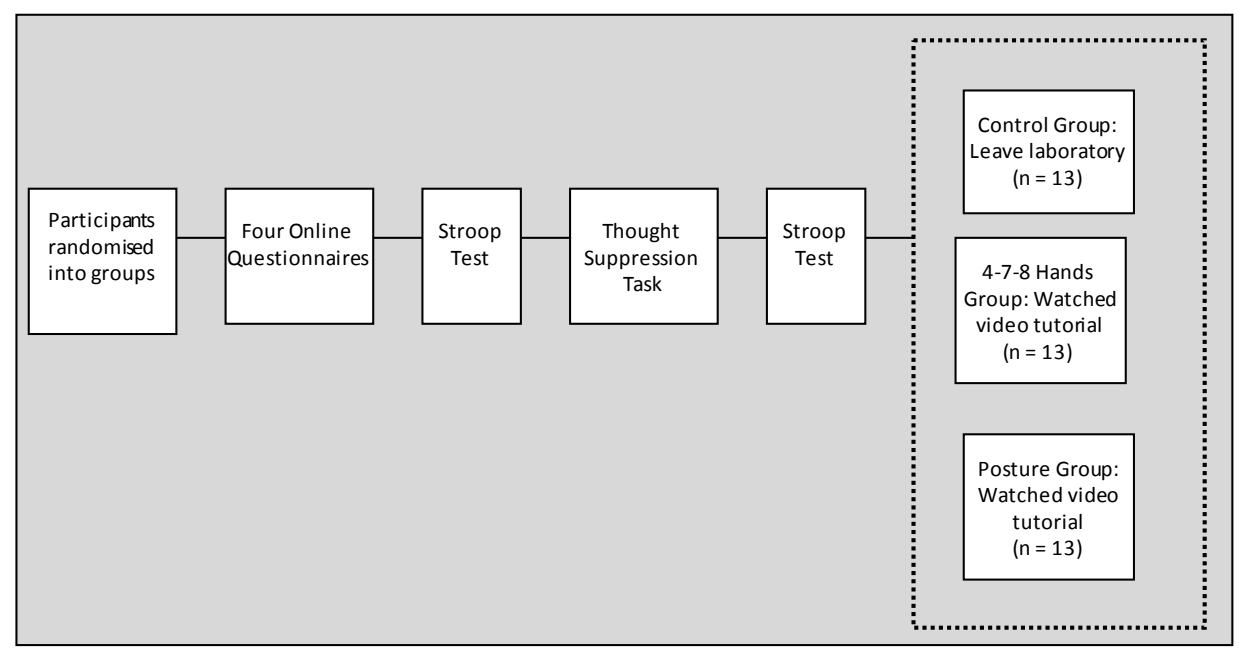

Figure 1.

Six phases of testing at pre-test. The sizes of the figures bear no weight or reflection on the type of task administered. They are only for visual effect.

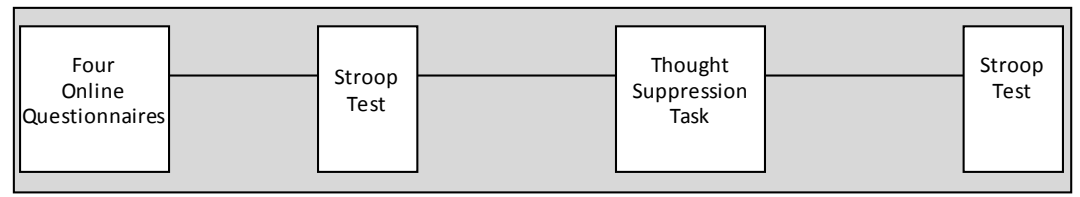

Figure 2.

Four phases of testing at post-test. The sizes of the figures bear no weight or reflection on the type of task administered. They are only for visual effect. 
To control for the potential confounding variable of exam stress, participants were tested during the beginning and middle of university semesters.

\section{Design}

The study was a 3 (group type: Control, 4-7-8, and Posture) $\times 2$ (time: pre-test and post-test) mixed design. Participants were randomly allocated to either the Control group, or an intervention group, either 4-7-8 Hands or Posture. The overarching dependent variables were: emotion control, measured by PSS and DTS, thought control, measured by MAAS, performance control, measured by BSCS, and impulse control, measured by Stroop.

\section{Results}

Prior to analysis the data was screened and assumptions were met. Each of the 39 participants in this study was tested at pretest and post-test. Participants in the two intervention groups reported high compliance performing the willpower strengthening exercises over the three days. All participants in the intervention groups returned completed monitoring forms, which showed adherence to performing the willpower strengthening exercises $80 \%-100 \%$ of the time. The high compliance and adherence rates support the hypothesis that the willpower strengthening exercises were feasible for university students.

A MANOVA indicated a nonsignificant interaction effect of group type by time, Wilks's $\Lambda=.78, F(10,64)=.83, p=.600$, $\eta^{2}=.12$, indicating that the five variables, BSCS, PSS, DTS, MAAS, and Stroop, did not significantly vary from pre-test to post-test, as a function of the type of group participants were allocated to. Likewise, the results indicated a nonsignificant main effect of group type, Wilks's $\Lambda=.85, F(10,64)=.56, p$ $=.837, \eta^{2}=.081$, suggesting that there were no significant variances in the dependent variables, as a function of the type of group participants were allocated to. These results do not support the hypothesis that the willpower strengthening exercises would lead to improvements in willpower strength. However, although the results were nonsignificant, the directional change in means did support the hypothesis, as outlined in Table 1. Participants in the active intervention groups tended to improve on BSCS, PSS, DTS, and MAAS, compared to the control group.

The results indicated a significant main effect of time,
Wilks's $\Lambda=.71, F(5,32)=2.60, p=.044, \eta^{2}=.29$. Univariate analysis, evaluating sphericity assumed, was conducted to follow up on this main effect. Results revealed a significant main effect across time for DTS $\left(F(1,36)=5.34, p=.027\right.$, partial $\eta^{2}$ $=.13$, observed power $=.61)$ and Stroop $(F(1,36)=8.96, p$ $=.005$, partial $\eta^{2}=.20$, observed power $=.83$ ). The significant effect across time for Stroop implied that the mean of Stroop scores at pre-test $(M=4.08, S D=3.50)$ were significantly higher than the mean of Stroop scores at post-test $(M=1.87$, $S D=3.21, t(38)=3.062, p=.002)$. This was not as expected, as it was hypothesised that repeated practice of willpower strengthening exercises would improve impulse control. Additionally, the positive means suggest that scores in the second administration of the Stroop test in each session were higher after completing the thought suppression task. This was also not as expected, as it was hypothesised that participants would not perform as well on the Stroop test after exerting self-control in the thought suppression task. However, although participants appeared to improve more in their performance on the Stroop at pre-test than at post-test, the baseline scores did significantly improve from pre-test $(M=19.51, S D=5.19)$ to post-test $(M=$ 24.72, $S D=4.24, t(38)=-7.67, p<.01)$. Therefore, although participants showed greater improvements in their two Stroop scores at pre-test, their baseline Stroop scores were higher at post-test.

Qualitative feedback was obtained from the participants regarding the feasibility of implementing the willpower strengthening exercises with university students. Overall, participants reported positive comments about the postural adjustment techniques, for example, "I found pausing to adjust my posture improved my mood”. Participants’ feedback regarding practicing the 4-7-8 Hands exercise was conflicting. Positive comments included, "I found it calmed me down", and "it made me think about my breathing”, while more constructive criticism included, "I did not like practicing the exercise when in class, as I found opening and closing my hands, not very subtle.” The feedback provides support for the hypothesis that the willpower strengthening exercises were able to be carried out by university students' despite a busy schedule.

\section{Discussion}

The aim of this present study was to evaluate the feasibility and efficacy of intense brief willpower strengthening exercises with university students. To the researchers' knowledge this is

Table 1.

Means and standard deviations of dependent variables for each group type.

\begin{tabular}{|c|c|c|c|c|c|c|c|c|c|c|c|c|}
\hline & \multicolumn{4}{|c|}{ Control $^{\mathrm{a}}$} & \multicolumn{4}{|c|}{ 4-7-8 Hands ${ }^{\mathrm{a}}$} & \multicolumn{4}{|c|}{ Posture $^{\mathrm{a}}$} \\
\hline & \multicolumn{2}{|c|}{$\mathrm{T} 1$} & \multicolumn{2}{|c|}{$\mathrm{T} 2$} & \multicolumn{2}{|c|}{$\mathrm{T} 1$} & \multicolumn{2}{|c|}{$\mathrm{T} 2$} & \multicolumn{2}{|c|}{$\mathrm{T} 1$} & \multicolumn{2}{|c|}{$\mathrm{T} 2$} \\
\hline & $M$ & $S D$ & $M$ & $S D$ & $M$ & $S D$ & $M$ & $S D$ & $M$ & $S D$ & $M$ & $S D$ \\
\hline BSCS & 39.46 & 9.77 & 39.31 & 10.43 & 41.23 & 7.42 & 41.92 & 7.73 & 39.62 & 8.78 & 41.46 & 7.46 \\
\hline PSS & 16.15 & 8.59 & 17.23 & 7.79 & 16.85 & 9.37 & 15.39 & 7.58 & 18.39 & 5.95 & 17.39 & 7.27 \\
\hline DTS & 3.33 & .62 & 3.37 & .79 & 3.01 & 1.11 & 3.09 & 1.09 & 3.02 & .69 & 3.32 & .63 \\
\hline MAAS & 3.69 & 1.07 & 3.68 & 1.22 & 3.49 & .77 & 3.54 & .73 & 3.46 & .90 & 3.51 & .90 \\
\hline Stroop & 3.92 & 4.41 & 2.00 & 2.74 & 4.46 & 3.38 & 1.69 & 3.59 & 3.85 & 2.23 & 1.92 & 3.48 \\
\hline
\end{tabular}

Note: T1 = Pre-test; T2 = Post-test; BSCS = Brief Self-Control Scale; PSS = Perceived Stress Scale; DTS = Distress Tolerance Scale; MAAS = Mindfulness Attention Awareness Scale; Stroop $=$ first testing Stroop score minus second testing Stroop score. ${ }^{\mathrm{a}} n=13$. 
the first study evaluating willpower strengthening exercises over a three-day period as well as their effect across the four domains of willpower. The first hypothesis predicted that the willpower strengthening exercises would be feasible for university students to incorporate into their busy work schedules. University students have competing demands on their time, with academic obligations, such as assignments, studying for exams, and attending lectures, as well as busy social lives that consist of regular use of mobile phones, text messaging, and Facebook (Cotton, Dollard, \& de Jonge, 2002; Hanson, Drumheller, Mallard, McKee, \& Schlegel, 2013). Regardless of these potential time demands, the university students who participated in this study reported performing the willpower strengthening exercises $80 \%-100 \%$ of the time. This high compliance rate is encouraging and supports feasibility of implementing willpower strengthening exercises with university students. Additionally, the positive feedback received from the participants about their experiences with the exercises was encouraging. The results provided promising preliminary support for this first hypothesis.

The second hypothesis predicted that compared to a control group, the two willpower strengthening groups, namely Posture and 4-7-8 Hands, would report significant improvements in willpower across all the four domains of willpower. The results did not provide significant statistics to support this hypothesis, however, mean directional changes between the groups indicates support. Therefore, it could be speculated that the short period of time may not have been sufficient to allow for adequate improvements in willpower strength, which compared to Muraven et al.'s (1999) study which found significant improvements in willpower when utilising a longer two-week intervention period. This supports the supposition that willpower requires an adequate duration of strengthening to become significantly stronger (Muraven et al., 1999). Future research should consider replication of this study, allowing for a longer period of time to practice the willpower strengthening exercises.

The results suggested significant differences in means, across all three groups, between pre-test and post-test. All participants reported a significant improvement in distress tolerance across time ( $p=.0145)$. The overall improvement in DTS may be due to when in the week testing was conducted. Students were tested at pre-test at the beginning of the week and post-test towards the end of the week. Due to motivation, or the closer positive outlook of the weekend, students in general may have felt they were in a better state to tolerate distress than they were at the beginning of the week. In assessing distress tolerance, future research should consider varying when testing of pre-test and post-test takes place. For example, alternating between testing each session at both ends of the week may reduce the impact of potential confounding factors.

The results found that all groups significantly improved on their Stroop test performance across time $(p=.002)$. This was not expected. Justification for all groups to report significant improvements is likely to be due to practice effects, coupled with the short duration of the Stroop test. Assessing self-control in a brief and practical test demands willpower energy to be consumed over a small period of time, reducing its ability to differentiate between individuals. Longer versions assessing the Stroop effect, which have been used in past studies, have successfully measured impulse control, as well as contrast groups of individuals with high impulse control with those with low impulse control (Oaten \& Cheng, 2006a). The conflicting re- sults found in this study leads to the implication that, potentially, a longer version is more effective at assessing willpower strength. This is because a longer version requires the greatest amount of stamina willpower energy over time. Those with stronger willpower are expected to have the stamina to perform well, while those with weaker willpower are expected to become fatigued quicker and perform more poorly. It is recommended that future research use a longer version of the Stroop test to better differentiate individuals with weak and strong willpower resource.

Generalisability of the findings was limited due to the female gender bias of the sample and homogenous sample of university students. Despite nonsignificant results, which do not offer support for the efficacy of the interventions, this pilot study has many strengths. To the researchers' knowledge, this was the first study to evaluate intensive willpower strengthening strategies over a brief three-day period. The design, a randomised control pilot trial, adds to the rigour and robustness of the study. In addition, this study utilised advanced technology through the use of the iPad application and video tutorials, which were especially created for this study by the researchers. Additionally, this study addressed limitations in previous research, such as measuring willpower strength across all four domains and having protocols for the implementation of the interventions, such as using Meaning to Pause ${ }^{\circledR}$ bracelets. These bracelets were another form of innovative technology that had not been previously used in this field of research. Finally, the study had $80 \%$ $100 \%$ compliance rates as well as no attrition, which may have been due to the short time frame. These rates may be attributable, in part, to the brief, encouraging reminder text messages participants received each morning. The text messages were aimed at keeping participants engaged in the study. Additionally, the relatively short duration of the study meant participants did not need to spend a considerable amount of time carrying out the willpower strengthening exercises. These strengths support the recommendation that future research should replicate this study, extending the time period to practice the willpower strengthening exercises.

The benefits of developing willpower strengthening exercises for university students' willpower are important due to the association with improved academic performance, reductions in stress and healthier living habits (de Ridder et al., 2012; Oaten \& Cheng, 2006a). Therefore, further investigations into the feasibility and efficacy of willpower strengthening exercises, that students will readily adhere to, has the potential to pave the way to greater positive outcomes for students.

\section{REFERENCES}

American Psychological Association (2010). Stress in America findings. http://www.apa.org/index.aspx

Baumeister, R. F., \& Tierney, J. (2011). Willpower. New York, NY: Penguin Group.

Baumeister, R. F., Bratslavsky, E., Muraven, M., \& Tice, D. M. (1998). Ego depletion: Is the active self a limited resource? Journal of Personality and Social Psychology, 74, 1252-1265. http://dx.doi.org/10.1037/0022-3514.74.5.1252

Baumeister, R. F., Gailliot, M., DeWall, C. N., \& Oaten, M. (2006). Self-regulation and personality: How interventions increase regulatory success, and how depletion moderates the effects of traits on behavior. Journal of Personality, 74, 1-29. http://dx.doi.org/10.1111/j.1467-6494.2006.00428.x

Baumeister, R. F., Heatherton, T. F., \& Tice, D. M. (1994). Losing con- 
trol: How and why people fail at self-regulation. Sand Diego, CA: Academic Press.

Bebebe Co. (2012). The Stroop effect. iTunes.

https://itunes.apple.com/au/app/the-stroop-effect/id472707380?mt=8

Brown, K. W., \& Ryan, R. M. (2003). The benefits of being present: Mindfulness and its role in psychological well-being. Journal of Personality and Social Psychology, 84, 822-848. http://dx.doi.org/10.1037/0022-3514.84.4.822

Chiesa, A., \& Malinowski, P. (2011). Mindfulness-based approaches: Are they all the same? Journal of Clinical Psychology, 67, 404-424. http://dx.doi.org/10.1002/jclp.20776

Cohen, S., \& Williamson, G. (1988). Perceived stress in a probability sample of the United States. In S. Spacapan, \& S. Oskamp (Eds.), The social psychology of health: Claremont Symposium on Applied Social Psychology (pp. 31-67). Newbury Park, CA: Sage.

Cotton, S. J., Dollard, M. F., \& de Jonge, J. (2002). Stress and student job design: Satisfaction, well-being, and performance in university students. International Journal of Stress Management, 9, 147-162. http://dx.doi.org/10.1023/A:1015515714410

Davidson, D. J., Zacks, R. T., \& Williams, C. C. (2003). Stroop interference, practice, and aging. Aging Neuropsychology and Cognition, 10, 85-98. http://dx.doi.org/10.1076/anec.10.2.85.14463

de Ridder, D. T. D., Lensvelt-Mulders, G., Finkenauer, C., Stok, F. M., \& Baumeister, R. F. (2012). A meta-analysis of how trait self-control relates to a wide range of behaviors. Personality and Social Psychology Review, 16, 76-99. http://dx.doi.org/10.1177/1088868311418749

Friese, M., Messner, C., \& Schaffner, Y. (2012). Mindfulness meditation counteracts self-control depletion. Consciousness and Cognition, 21, 1016-1022. http://dx.doi.org/10.1016/j.concog.2012.01.008

Graham, C., \& Irish, K. (2010). Meaning to pause. http://www.meaningtopause.com

Hanson, T. L., Drumheller, K., Mallard, J. McKee, C., \& Schlegel, P. (2013). Cell phones, text messaging, and Facebook: Competing time demands of today's college students. College Teaching, 59, 23-30. http://dx.doi.org/10.1080/87567555.2010.489078

http://dx.doi.org/10.1348/135910706X96481

Hughes, B. M. (2005). Study, examinations, and stress: Blood pressure assessments in college students. Educational Review, 57, 21-36. http://dx.doi.org/10.1080/0013191042000274169

Institute for Mindfulness Studies (2011). 4-7-8 Hands. http://thelearnedhand.org/Learned_Hand_Exercises.html

Lee, E. (2012). Review of the psychometric evidence of the Perceived Stress Scale. Asian Nursing Research, 6, 121-127. http://dx.doi.org/10.1016/j.anr.2012.08.004

Muraven, M., \& Baumeister, R. F. (2000). Self-regulation and depletion of limited resources: Does self-control resemble a muscle? Psychological Bulletin, 126, 247-259. http://dx.doi.org/10.1037/0033-2909.126.2.247

Muraven, M., Baumeister, R. F., \& Tice, D. M. (1999). Longitudinal improvement of self-regulation through practice: Building self-control strength through repeated exercise. The Journal of Social Psychology, 139, 446-457.

http://dx.doi.org/10.1080/00224549909598404

Oaten, M., \& Cheng, K. (2006a). Improved self-control: The benefits of a regular program of academic study. Basic and Applied Social Psychology, 28, 1-16. http://dx.doi.org/10.1080/00224549909598404

Oaten, M., \& Cheng, K. (2006b). Longitudinal gains in self-regulation from regular physical exercise. British Journal of Health Psychological Society, 11, 717-733.

Segal, Z. V., Williams, J. M., \& Teasdale, J. D. (2002). Mindfulnessbased cognitive therapy for depression, New York, NY: The Guilford Press.

Simons, J. S., \& Gaher, R. M. (2005). The Distress Tolerance Scale: Development and validation of a self-report measure. Motivation and Emotion, 29, 83-102. http://dx.doi.org/10.1007/s11031-005-7955-3

Stroop, J. R. (1935). Studies of interference in serial verbal reactions. Journal of Experimental Psychology, 18, 643-662. http://dx.doi.org/10.1007/s11031-005-7955-3

Tangney, J. P., Baumeister, R. F., \& Boone, A. L. (2004). High selfcontrol predicts good adjustment, less pathology, better grades and interpersonal success. Journal of Personality, 72, 271-324. http://dx.doi.org/10.1111/j.0022-3506.2004.00263.x

Wegner, D. M., Schneider, D. J., Carter, S. R., \& White, T. L. (1987). Paradoxical effects of thought suppression. Journal of Personality and Social Psychology, 53, 5-13.

http://dx.doi.org/10.1037/0022-3514.53.1.5 